\title{
Early onset inflammatory bowel disease: manifestations, genetics and diagnosis
}

\author{
Bobak Moazzami ${ }^{1,2}$, Kasra Moazzami ${ }^{3,4}$, Nima Rezaei ${ }^{1,5,6}$ \\ ${ }^{1}$ Research Center for Immunodeficiencies, Children's Medical Center, Tehran University of Medical Sciences, Tehran, \\ Iran; ${ }^{2}$ Student Research Committee, Babol University of Medical Sciences, Babol, Iran; ${ }^{3}$ Massachusetts General Hospital, \\ Harvard Medical School, ${ }^{4}$ Network of Immunity in Infection, Malignancy and Autoimmunity (NIIMA), Universal Scientific \\ Education and Research Network (USERN), Boston, MA, USA; ${ }^{5}$ Department of Immunology, School of Medicine, Tehran \\ University of Medical Sciences, Tehran, Iran; ${ }^{6}$ Network of Immunity in Infection, Malignancy and Autoimmunity (NIIMA), \\ Universal Scientific Education and Research Network (USERN), Sheffield, UK. E-mail: rezaei_nima@tums.ac.ir \\ Received: 11th September 2017, Revised: 7th November 2017, 7th January 2018, Accepted: 7th January 2018
}

SUMMARY: Moazzami B, Moazzami K, Rezaei N. Early onset inflammatory bowel disease: manifestations, genetics and diagnosis. Turk J Pediatr 2019; 61: 637-647.

Crohn's disease and ulcerative colitis are immunologically mediated chronic inflammatory conditions, collectively referred to as inflammatory bowel diseases (IBD). While most studies have described the condition in the adult population, recent evidences suggest that IBD in children may represent an etiologically distinct disease from the adult onset IBD. Since a significant proportion of patients diagnosed with IBD demonstrate their clinical manifestations during childhood, knowledge about the disease progression, severity and diagnosis in this particular patient population is crucial. Therefore, in the present study, the clinical manifestations, recent advancements in the genetics of early onset IBD and the clinical approach to diagnoses of IBD in children are described.

Key words: Crohn's disease, inflammatory bowel diseases, interleukin-10.

Crohn's disease (CD) and Ulcerative colitis (UC) are two distinct types of gastrointestinal disorders, collectively defined as inflammatory bowel disease (IBD). IBD is an idiopathic, lifelong, destructive chronic inflammatory disease of the gastrointestinal tract. Deregulated balance of immune response, environmental triggers and genetic susceptibility are among the essential contributors in the development of IBD. ${ }^{1-3}$ As a consequence, every group of ages, races, gender and socioeconomic are at risk of developing to IBD. ${ }^{4}$

Population based studies have revealed that a large proportion of patients diagnosed with IBD develop their symptoms before 30 years of age. ${ }^{2,5}$ In addition, there are several studies that have shown an estimated $10 \%$ to $15 \%$ of patients are diagnosed with IBD under the age of $18 .{ }^{6-8}$
Therefore early-onset IBD is likely to represent a specific disorder with particular gene defects and phenotypic appearance compared to the adult population. ${ }^{9}$ Recently, IBD demographics have been changed due to the increasing rate of IBD onset that occur in childhood. Over the last 4 decades there has been an internationally increasing trend in the incidence of early onset IBD in pediatrics, according to European report. ${ }^{10-13}$ The rise in the incidence of childhood IBD could also have an impact on both emotional and physical development. ${ }^{14,15}$ In contrast to adults, children with early-onset IBD appear to have a more severe intestinal involvement and clinical course. ${ }^{16}$ Moreover, a positive family history of IBD is more common among children, suggesting a genetic association for IBD in this population. ${ }^{17,18}$ 
Among these patients with early onset IBD, a subset has recently been identified with the onset of disease occurring before 6 years of age. This group of very-early-onset IBD (VEOIBD) have shown to have unique clinical presentations with greater duration of disease, extensive colonic inflammation, and poor response to standard therapies, including biologic agents. ${ }^{19}$ Also, a much stronger family history of the disease is present in this subset of pediatric IBD. In addition to the different disease phenotype between patients with early onset IBD and VEOIBD, the latter group has also been associated with distinct genetic variants, often involving genes associated with primary immunodeficiencies. ${ }^{19,20}$

\section{Manifestations}

In general, IBD manifestations are highly dependent on the areas of gastrointestinal tract involvement. UC and CD may present with similar clinical complains and symptoms among both children and adults. Although UC and $\mathrm{CD}$ are two distinct GI disorders, both of them could be presenting with symptoms such as abdominal pain, vomiting, diarrhea, rectal bleeding and abdominal cramp. Also, there are a number of clinical, endoscopic and histopathological factors that can help in distinguishing between these two major forms of IBD.

$\mathrm{UC}$ is limited to large intestine and involves in superficial inflammatory process, while, CD can affect any part of the gastrointestinal tract, from mouth to anus. UC only affects colon and rectum..$^{21-23}$ In the pediatric population, the most prominent feature is bloody diarrhea, also known as "Hematochezia". The severity of its clinical presentations is based on the extent of the disease process. ${ }^{23}$ UC typically begins in the rectum and it can be continuously extended to terminal ileum which is termed backwash ileitis. ${ }^{24,25}$ UC symptoms may be varied from mild abdominal discomfort to painful bowel movements and abdominal cramping. Increasing rate of anemia is noted in patients with UC as a result of inflammation along with chronic blood loss (84\%). ${ }^{26,27}$ In almost all cases of UC, inflammation of anorectal region (also known as proctitis) results in urgency of defecation which is called "Tenesmus". Pancolitis is defined as the involvement of the entire colon, may occur in severe forms of UC. In one study, $74.7 \%$ of children with early onset IBD presented with pancolitis at the time of diagnosis. ${ }^{17}$

In contrast to UC, $\mathrm{CD}$ is characterized by discontinuous and transmural nature with inflammation extending from mucosa to serosa which could affect any part of gastrointestinal tract. ${ }^{17}$ The initial manifestations of $\mathrm{CD}$ may be abdominal pain (44\%) which is usually accompanied by diarrhea. ${ }^{28}$ In one study only $25 \%$ of pediatric patients present with classic triad of abdominal pain, weight loss and diarrhea. ${ }^{29}$ Diarrhea is often in large-volume, intermittent and non-bloody, depending on which part of the small or large intestine is involved. In severe cases, bowel movements could be exceeding more than 20 times per day. The most common symptom of CD in pediatrics is weight loss occurred in $90 \%$ of cases. ${ }^{30,31}$ One of the most commonly observed regions in gastrointestinal tract that is affected by $\mathrm{CD}$ is terminal ileum ( $71 \%$ of pediatrics patients) and right colon (71\%). ${ }^{17}$ This involvement usually presents with symptoms such as malabsorption which could be resulting in weight loss and anorexia. Limbergen et al. ${ }^{17}$ demonstrated that childhood-onset CD is more likely to progress to more extensive anatomic involvement including small bowel, large bowel, and upper GI tract. Other common symptoms such as persistent vomiting and severe abdominal pain are caused by small intestinal stenosis involving the pylorus or duodenum. Perianal complications (29\% in pediatric population) such as fistulae, abdominal abscesses and intestinal strictures are also commonly seen in CD..$^{32}$ The incidence of strictures have been shown to be similar to adults with approximately $30 \%$ of patients experiencing this complication during the course of their disease. ${ }^{33}$

Extraintestinal manifestations of both UC and $\mathrm{CD}$ include liver involvement (primary sclerosing cholangitis), arthritis and skin rashes such as erythema nodosum and pyoderma gangrenosum. Arthritis is the most common extraintestinal manifestation among pediatric population $(32,34-36)$ (Table I). 
Table I. Clinical and Histologic Characteristic of CD and UC in Children.

\begin{tabular}{lll}
\hline & $\mathrm{CD}$ & $\mathrm{UC}$ \\
\hline Clinical Manifestation & & ++ \\
Abdominal pain & ++ & ++ \\
Diarrhea & ++++ & ++++ \\
Hematochezia & ++ & ++ \\
Weight loss & ++ & \\
Extra-intestinal manifestations & & + \\
Toxic megacolon & + & Rare \\
Primary sclerosing cholangitis & + & + \\
Erythema nodosum & + & ++ \\
Arthritis & +++ & Rare \\
Pyoderma gangraenosum & Very rare & + \\
Fistula/abscess/stricture & ++ & Colon and rectum \\
Distribution of the disease in & Mouth to anus (ileum the most common) \\
gastrointestinal tract & & \\
Location & Transmural & Mucosal \\
Histology & Tissue granuloma & Crypt abscess \\
\hline
\end{tabular}

+ indicates presence in $0-25 \%$ of patients; ++ indicates presence in

$26-50 \%$ of patients; +++ indicates presence in $51-75 \%$ of patients;

++++ indicates presence in $76-100 \%$ of patients.

Table II. Differences in the Clinical Manifestations Between Early and Late Onset IBD.

\begin{tabular}{lll}
\hline Clinical Manifestation & Early Onset IBD & Late onset IBD \\
\hline $\begin{array}{lll}\text { Severity of disease } \\
\text { Ulcerative colitis }\end{array}$ & Higher & Lower \\
Crohn's disease & Higher & Lower \\
Requirement for surgery & & \\
Ulcerative colitis & Higher & Lower \\
Crohn's disease & Lower & Higher \\
Nutritional Impairment & & \\
Ulcerative colitis & Higher & Lower \\
Crohn's disease & Higher & Lower \\
\hline
\end{tabular}

\section{Differences between early and late onset IBD}

The clinical manifestations of early-onset IBD may be different than adult onset disease (Table II). ${ }^{37}$ Among the UC population, it has been shown that extensive colitis is found to be twice more common among children than adults. ${ }^{9,38}$ Also, the median time to operation in the pediatric population is significantly shorter than in adults. ${ }^{18,39}$ Among patients affected by $\mathrm{CD}$, those with early-onset disease are shown to have a much more extensive disease involvement than adult-onset IBD. ${ }^{40}$ However, fewer patients in the early-onset group require surgery compared with adultonset CD patients. These distinct phenotypic characteristics suggest that pediatriconset IBD may have different pathogenic mechanisms from adult-onset IBD. ${ }^{17,41}$ This notion has been supported by the findings in 
recent years that specific mutations are present in many cases of early-onset IBD which points to pathogenic mechanisms affecting this group of patients. ${ }^{42,43}$ Since many of these mutations have been shown to harbor a recessive mode of inheritance, parental consanguinity can potentially increase the susceptibility of these individuals to manifest the disease in young age. This notion, however, has not been confirmed by larger studies to date.

Nutritional impairment is among the common clinical manifestations of early-onset IBD. . $^{14,44,45}$ Loss of appetite and impaired absorption are seen in both early-onset CD and UC with up to three quarters of patients with active disease experience some degree of malnutrition during their course of disease. However, delay of growth and puberty secondary to malnutrition is mostly seen in $\mathrm{CD}$, and less frequently encountered in pediatric onset UC. ${ }^{29}$ Enteral nutrition, defined by liquid formula diet by mouth or nasogastric tube, has been used for over 30 years in the CD population. ${ }^{46-48}$ While limited evidence exists regarding the role of enteral nutrition in the early onset UC population, provision of adequate nutrition still remains important in this patient population..$^{49,50}$

It has been suggested that patients affected by early-onset IBD have lower response rates to conventional anti-inflammatory and immunomodulatory therapy. However, there is a paucity of well-designed studies to support this hypothesis.

Histological investigation is paramount in the work up of patients suspected to have earlyonset IBD, not only to differentiate IBD-like features, but also to exclude other established pathologies such eosinophilic or allergic gastrointestinal disease and infection.

Laboratory tests such as immunoglobulin measurements, flow cytometry and oxidative burst assays could be utilized as an important tool in differentiating different subgroups of $\mathrm{IBD}^{51,52}$, such as those who develop the disease before the age of 2 years old, those with excessive autoimmunity, or those with severe perianal disease. For instance, flow cytometry analysis of XIAP and FOXP3 expression can assist in the diagnosis of significant proportion of patients with XLP2 and IPEX. Flow cytometry can detect functional defects in signaling pathways of MDP among patients with XIAP deficiency. ${ }^{53,54}$ Detection of antibodies against enterocytes can be useful in the diagnosis of autoimmune enteropathy, particularly among patients with IPEX syndrome. ${ }^{52}$ Additional tests for other rare genetic defects may also help in the detection of subgroups of earlyonset IBD, but are usually only available at specialized laboratories, often as part of research projects. ${ }^{55}$

Among patients with early-onset IBD, approximately one fifth under the age of 6 and one third of patients under 3 years of age are labeled as unclassified IBD $^{56}$, which reflects a lack of a refined phenotyping tool to categorize all patients affected by IBD at a young age. Incomplete diagnostic workup is also partly responsible for the lack of better characterization of this group of patients.

\section{Genetics}

Single nucleotide polymorphism (SNP) has tremendously helped in understanding the genetics of human IBD $(57,58)$, providing insights into the genetic complexity underlying these inflammatory conditions. However, the functional relevance of most of these susceptibility genes is unclear. ${ }^{59,60}$

Several pathways have been discovered by analyzing genetic loci implicated in patients with IBD, that are crucial for intestinal integrity and homeostasis such as, epithelial barrier function, innate and adaptive immune regulation, reactive oxygen species (ROS) generation and autophagy ${ }^{42,61-63}$ (Table III).

Very early onset IBD and PIDs: IL-10, IL10Ra, IL-10Rb, NFAT5, TTC7A

\section{IL-10, IL-10Ra, IL-10Rb}

Interleukin-10 (IL-10) is an anti-inflammatory cytokine that has several pleiotropic effects on immunoregulatory cells including $\mathrm{T}$ cells, B cells and monocytes. ${ }^{64}$ This cytokine is encoded by IL-10 gene, located on chromosome $1 .{ }^{65}$ The receptor for IL-10 is consisted of two subunits including IL-10 receptor-1(IL10Ra) and IL10 receptor 2 (IL10Rb) proteins. ${ }^{64}$ IL10R1 is 
Table III. Genes with Functions Associated with Early vs Late Onset IBD.

\begin{tabular}{|c|c|c|c|c|}
\hline Gene & Chromosome & $\begin{array}{l}\text { Associated with } \\
\text { Early-onset IBD }\end{array}$ & $\begin{array}{l}\text { Associated with } \\
\text { Late-onset IBD }\end{array}$ & Function \\
\hline NOD2 & 16 & Yes & No & $\begin{array}{l}\text { killing of intracellular pathogens, } \\
\text { Innate immune recognition }\end{array}$ \\
\hline CARD 9 & 9 & Yes & Yes & $\begin{array}{l}\text { NFkB activation and/or regulation, } \\
\text { positive regulator of apoptosis }\end{array}$ \\
\hline Interleukin-10 & 1 & Yes & No & maintaining intestinal homeostasis \\
\hline TTC7A & 2 & Yes & Yes & $\begin{array}{l}\text { modulating immune homeostasis, cell } \\
\text { cycle control }\end{array}$ \\
\hline NFAT5 & 16 & Yes & Yes & $\begin{array}{l}\text { regulate immune response including } \\
\text { cytokine production }\end{array}$ \\
\hline LRBA & 4 & Yes & No & $\begin{array}{l}\text { activation of receptor complexes, } \\
\text { secretion of immune effector } \\
\text { molecules }\end{array}$ \\
\hline MEFV & 16 & Yes & No & $\begin{array}{l}\text { regulating of the inflammasome } \\
\text { platform }\end{array}$ \\
\hline XIAP & $X$ & Yes & No & inhibits apoptosis \\
\hline
\end{tabular}

CD: Crohn's Disease UC: Ulcerative Colitis NOD2: Nucleotide-binding oligomerization domain-containing protein 2 CARD9: Caspase recruitment domain-containing protein 15 TTC7A: Tetratricopeptide repeat domain 7A NFAT5: Nuclear factor of activated T-cells 5 LRBA: LPS responsive beige-like anchor protein XIAP: X-linked inhibitor of apoptosis protein

unique to the interleukin-10 receptor, while, IL10R2 is a subunit of the receptors for several additional cytokines (e.g., interleukin-22 and interleukin-26). ${ }^{65,66}$ Interleukin-10 is a cytokine synthesis inhibitory factor (CSIF) and limits the secretion of proinflammatory cytokines, such as tumor necrosis factor $\alpha$ $\left(\right.$ TNF- $\alpha$ ) and interleukin-12. ${ }^{67}$

Deficiency in interleukin-10 results in prolonged activation of mononuclear cells on exposure to bacterial particles, which in turn augments the efflux of inflammatory cytokines such as TNF-a, causing damage to the intestinal mucosa. ${ }^{68}$ The presence of severe inflammatory bowel disease is the most prominent phenotype in patients with IL10Ra or IL10Rb deficiency. ${ }^{69}$

\section{TTC7A}

Tetratricopeptide repeat domain 7A (TTC7A) is a gene present on chromosome 3 that encodes a protein that has shown to have diverse functions in cell cycle control such as protein transport, phosphate turnover, and protein trafficking or secretion. This protein also has a role in acting as chaperones or scaffolding proteins. ${ }^{70,71}$
Recently, mutations in the TTC7A gene were found to cause multiple intestinal atresia (MIA). Mutation in this gene has also shown to be associated with severe infantile or very early onset IBD. ${ }^{70,72}$

\section{NFAT5}

Nuclear factor of activated T-cells 5, also known as NFAT5, is a human gene located on chromosome 16 that encodes a transcription factor that play a central role in inducible gene transcription during the immune response including cytokine production. ${ }^{73}$ In addition, this protein has shown to regulate gene expression induced by osmotic stress in mammalian cells. ${ }^{74}$ Recent studies indicate that mutations in this gene can cause hyperosmolarity and hyperosmotic stress within the colon, which in turn triggers inflammation. ${ }^{75}$ Observational studies in human patients with IBD have shown elevated osmolarity in fecal fluid within the colon in these patients. ${ }^{76,77}$ Moreover, elevated fecal osmolarity has shown to closely correlate with disease severity in these patients. ${ }^{77,78}$ 
PIDs associated with IBD: LRBA, FMF, XIAP, Blau syndrome

Primary immunodeficiency disease (PID) are a group of more than 150 genetically heterogeneous disorders involving innate and adaptive immune system which include antibody production defects (B-cell defects), cellular or combined defects (T-cell defects or B-cell and T-cell defects), phagocytic cell defects and complement defects.

Gastrointestinal manifestations are a hallmark of patients with PID. Given the fact that the intestine is the largest lymphoid organ in the body, any dysregulation in the humoral or cell-mediated immunity could affect the integrity of the gastrointestinal tract resulting in a diverse range of manifestations. A number of PID disorders have been linked with the presence of IBD. ${ }^{79}$

\section{LRBA deficiency}

Deficiency in the "Lipopolysaccharide (LPS)responsive vesicle trafficking, beach- and anchor-containing" gene is a rare genetic disorder of the immune system characterized by autoimmunity, lymphoproliferation, and immune deficiency. ${ }^{80}$ The gene encodes a protein that plays a major immuno-regulatory role in the expression, function, and trafficking of cytotoxic $\mathrm{T}$ lymphocyte-associated protein 4 which acts as an inhibitory checkpoint for the immune response. ${ }^{81}$ Patients with LRBA deficiency present with infections occurring in the eyes, skin and gastrointestinal tract. Many patients also present with chronic diarrhea and inflammatory bowel disease. Other clinical features can include hepatosplenomegaly, reoccurring warts, growth retardation, allergic dermatitis, and arthritis. ${ }^{80,81}$

\section{FMF}

Familial Mediterranean fever (FMF), is a hereditary inflammatory disorder caused by mutations in the gene MEFV, located on chromosome $16 .{ }^{82}$ The gene encodes pyrin, a protein playing a major role in the regulation of the inflammasome platform in addition to interacting with the gene product of NLRP3, an important active member of the inflammasome. ${ }^{83}$ The NLRP3 region was recently reported to be associated with Crohn's disease (CD) susceptibility. ${ }^{84}$
$X L A P$

X-linked inhibitor of apoptosis protein (XIAP), is a protein produced by XIAP gene located on the $\mathrm{X}$ chromosome and plays a major role in inhibiting apoptotic cell death induced by viral infection or overproduction of caspases. ${ }^{85,86}$ The protein functions by binding to caspase 3, 7 and 9 and inhibiting these factors. ${ }^{87}$ Deregulation of XIAP can result in tumorogenesis, neurodegeneration and autoimmunity as well as to a rare and severe type of IBD..$^{88,89}$

\section{Blau Syndrome}

Blau syndrome (BS) is a rare systemic inflammatory disease characterized by pediatric onset granulomatous arthritis, uveitis and skin rash. ${ }^{90}$ The syndrome is caused by mutations in the NOD2 gene (16q12), which causes activation of nuclear factor kappa B which in turn up-regulates pro-inflammatory cytokine transcriptions. This results in alterations in the innate immune response causing inflammation, cell death and IBD..$^{91,92}$

\section{Other gene variations, associated with IBD: NOD2, CARD9}

\section{NOD2}

The first gene polymorphism recognized to be related to IBD was NOD2 located on chromosome 16. Also known as caspase recruitment domain-containing protein 15 (CARD15), the gene encodes a protein which plays a critical role in the innate immune system by recognizing bacterial peptidoglycan product muramyl dipeptide (MDP) and initiating an immune response. ${ }^{93}$ Expression of NOD2 induces autophagy by MDP stimulation, resulting in the luminal bacterial replication regulation. ${ }^{94,95}$ Mutations in CARD15 gene have also shown to cause an impairment in the clearance of salmonella from epithelial cells. ${ }^{96}$

\section{CARD 9}

CARD9 is a member of the caspase-associated recruitment domain (CARD) protein family. It encodes an adaptor molecule signal which is critical for NF-kB activation and participation in apoptosis signaling. ${ }^{97}$ This gene also plays an important role in modulating innate immune 
responses to intracellular pathogens such as viral, bacterial and fungal motifs. ${ }^{98-100} \mathrm{~A}$ defect in CARD9 function can lead to immune disorder and increased susceptibility to intracellular pathogens such as candidiasis. ${ }^{101}$ It has been suggested that defects in this gene may be implicated as a predisposition factor for developing IBD.

\section{Diagnosis}

IBD is diagnosed by the confirmation of chronic inflammation in the gastrointestinal (GI) tract and ruling out other causes of inflammation such as infectious diseases, primary immunodeficiency disorders (PIDs) and allergic diseases. ${ }^{102}$

The accurate diagnosis for all patients with suspected IBD should be based on a full medical history including intestinal and extra-intestinal manifestations. Physical examination should include growth velocity, anthropometric measurements and the inspection of oral and perianal involvement. ${ }^{103}$ Laboratory investigation should comprise ESR, CRP and platelet count (as a sign of inflammation), anemia workup and signs of malnutrition. ${ }^{51}$ Growth retardation may be the only initial symptom at the time of diagnosis. ${ }^{14,29,104}$ Endoscopic and histological assessment of the both small bowel and large bowel mucosal pinch biopsies should be performed. ${ }^{105-107}$ Stool examination and fecal cultures are needed in order to exclude infectious causes of diarrheal illness. ${ }^{51}$

Previously, performing small bowel imaging has been recommended for all cases of IBD particularly in patients suspected with Crohn's disease, atypical presentations of ulcerative colitis and unclassified IBD. ${ }^{108}$

Despite recent endeavors in standardization of definitions and classifications of pediatrics IBD as well as advances in diagnostic imaging modalities, the exact diagnosis of pediatric IBD is still highly dependent on choosing the best diagnostic tests and appropriate interpretation of the results of the workup. ${ }^{108}$

The diagnosis of UC is based on the identification of continuous inflammation of the colon by colonoscopy and colonic biopsies. Macroscopic features of UC include diffuse mucosal granularity, friability, purulent exudates, edema, and erythema with or without ulceration. ${ }^{109}$ Histological evaluations can reveal the presence of active inflammation defined as neutrophils infiltrations within the crypt lumen as well as crypt forming abscesses. ${ }^{110}$ Chronic features of UC include crypt architectural distortion with an increase in chronic inflammatory cells in the lamina propria and increased lymphocytes and plasma cells between crypt bases and the muscularis mucosae (termed as plasmacytosis). ${ }^{8}$ Macroscopic rectal sparing may be seen in about $10 \%$ to $30 \%$ of children diagnosed with UC. ${ }^{111}$ on the other hand microscopic rectal sparing is infrequently seen in UC. ${ }^{112}$

A single gold standard for the diagnosis of CD has not yet been introduced. CD is diagnosed by a combination of clinical evaluation and histological and radiological findings. The diagnosis of $\mathrm{CD}$ is based on findings of discontinuous involvement of GI tract.

According to the Paris classification, typical features of pediatric $C D$ are as follows: Macroscopic features such as mucosal aphthous ulcers, fat wrapping, stenosis, structuring, skip lesions, bowel wall thickening and perianal lesions such as fistula, abscesses and skin tags. Microscopic features include noncaseating granuloma, transmural infiltration of inflammatory cells and submucosal fibrosis. ${ }^{111}$ The presence of any well-formed non-caseating granuloma anywhere in the gastrointestinal tract should prompt the diagnosis of CD. ${ }^{111}$

Pediatric IBD represents a specific disorder with distinct clinical manifestations, genetics and diagnostic criteria that differ from adult onset disease. The number of susceptibility genes related to pediatric onset IBD continues to increase, leading to a deeper understanding of the pathogenesis involving this distinct clinical entity. Identification of the responsible genetic variants could help in defining specific disease phenotypes as well as novel therapeutic targets. Future studies are required to identify the interactions between genes and environmental factors that could play a role in the pathogenesis of these diseases and provide optimal medical therapy. 


\section{REFERENCES}

1. Brant SR. Update on the heritability of inflammatory bowel disease: the importance of twin studies. Inflamm Bowel Dis 2011; 17: 1-5.

2. Xavier RJ, Podolsky DK. Unravelling the pathogenesis of inflammatory bowel disease. Nature 2007; 448: 427-434.

3. Podolsky DK. Inflammatory bowel disease. N Engl J Med 2002; 347: 417-429.

4. Sonnenberg A. Occupational distribution of inflammatory bowel disease among German employees. Gut 1990; 31: 1037-1040.

5. Baldassano RN, Piccoli DA. Inflammatory bowel disease in pediatric and adolescent patients. Gastroenterol Clin North Am 1999; 28: 445-458.

6. Feuerstein JD, Cheifetz AS. Ulcerative colitis: epidemiology, diagnosis, and management. Mayo Clin Proc 2014; 89: 1553-1563.

7. Ye Y, Pang Z, Chen W, Ju S, Zhou C. The epidemiology and risk factors of inflammatory bowel disease. Int J Clin Exp Med 2015; 8: 22529-22542.

8. Kugathasan S, Judd RH, Hoffmann RG, et al; Wisconsin Pediatric Inflammatory Bowel Disease Alliance. Epidemiologic and clinical characteristics of children with newly diagnosed inflammatory bowel disease in Wisconsin: a statewide population-based study. J Pediatr 2003; 143: 525-531.

9. Nieuwenhuis EE, Escher JC. Early onset IBD: what's the difference? Dig Liver Dis 2008; 40: 12-15.

10. Olafsdottir EJ, Fluge G, Haug K. Chronic inflammatory bowel disease in children in western Norway. J Pediatr Gastroenterol Nutr 1989; 8: 454-458.

11. Vind I, Riis L, Jess T, et a; DCCD Study Group. Increasing incidences of inflammatory bowel disease and decreasing surgery rates in Copenhagen City and County, 2003-2005: a population-based study from the Danish Crohn colitis database. Am J Gastroenterol 2006; 101: 1274-1282.

12. Cosgrove M, Al-Atia RF, Jenkins HR. The epidemiology of paediatric inflammatory bowel disease. Arch Dis Child 1996; 74: 460-461.

13. Benchimol EI, Fortinsky KJ, Gozdyra P, Van den Heuvel M, Van Limbergen J, Griffiths AM. Epidemiology of pediatric inflammatory bowel disease: a systematic review of international trends. Inflamm Bowel Dis 2011; 17: 423-439.

14. Motil KJ, Grand RJ, Davis-Kraft L, Ferlic LL, Smith EO. Growth failure in children with inflammatory bowel disease: a prospective study. Gastroenterology 1993; 105: 681-691.

15. Kirschner BS. Permanent growth failure in pediatric inflammatory bowel disease. J Pediatr Gastroenterol Nutr 1993; 16: 368-369.

16. Michener WM, Farmer RG, Mortimer EA. Long-term prognosis of ulcerative colitis with onset in childhood or adolescence. J Clin Gastroenterol 1979; 1: 301-305.
17. Van Limbergen J, Russell RK, Drummond HE, et al. Definition of phenotypic characteristics of childhoodonset inflammatory bowel disease. Gastroenterology 2008; 135: 1114-1122.

18. Vernier-Massouille G, Balde M, Salleron J, et al Natural history of pediatric Crohn's disease: a population-based cohort study. Gastroenterology 2008; 135: 1106-1113.

19. Bianco AM, Girardelli M, Tommasini A. Genetics of inflammatory bowel disease from multifactorial to monogenic forms. World J Gastroenterol 2015; 21 : 12296-12310.

20. Snapper SB. Very-early-onset inflammatory bowel disease. Gastroenterol Hepatol (N Y). 2015; 11: 554556.

21. Freeman HJ. Natural history and clinical behavior of Crohn's disease extending beyond two decades. J Clin Gastroenterol 2003; 37: 216-219.

22. Baumgart DC, Carding SR. Inflammatory bowel disease: cause and immunobiology. Lancet 2007; 369: $1627-1640$.

23. Hanauer SB. Inflammatory bowel disease. N Engl J Med 1996; 334: 841-848.

24. Goldstein N, Dulai M. Contemporary morphologic definition of backwash ileitis in ulcerative colitis and features that distinguish it from Crohn disease. Am J Clin Pathol 2006; 126: 365-376.

25. Haskell H, Andrews CWJr, Reddy SI, et al. Pathologic features and clinical significance of "backwash" ileitis in ulcerative colitis. Am J Surg Pathol 2005; 29: 1472 1481.

26. Wang GF, Ren JA, Liu S, et al. Clinical characteristics of non-perianal fistulating Crohn's disease in China: a single-center experience of 184 cases. Chin Med J (Engl) 2012;125: 2405-2410.

27. Stein J, Hartmann F, Dignass AU. Diagnosis and management of iron deficiency anemia in patients with IBD. Nat Rev Gastroenterol Hepatol 2010; 7: 599-610.

28. Gupta N, Bostrom AG, Kirschner BS, et al Presentation and disease course in early-compared to later-onset pediatric Crohn's disease. Am J Gastroenterol 2008; 103: 2092-2098.

29. Sawczenko A, Sandhu BK. Presenting features of inflammatory bowel disease in Great Britain and Ireland. Arch Dis Child 2003; 88: 995-1000.

30. Bollegala N, Nguyen GC. Transitioning the adolescent with IBD from pediatric to adult care: A review of the literature. Gastroenterol Res Pract 2015; 2015: 853530.

31. Griffiths AM. Specificities of inflammatory bowel disease in childhood. Best Pract Res Clin Gastroenterol 2004; 18: 509-523.

32. Passo MH, Fitzgerald JF, Brandt KD. Arthritis associated with inflammatory bowel disease in children. Relationship of joint disease to activity and severity of bowel lesion. Dig Dis Sci 1986; 31: 492 497. 
33. Freeman HJ. Comparison of longstanding pediatriconset and adult-onset Crohn's disease. J Pediatr Gastroenterol Nutr 2004; 39: 183-186.

34. Dotson JL, Hyams JS, Markowitz J, et al. Extraintestinal manifestations of pediatric inflammatory bowel disease and their relation to disease type and severity. J Pediatr Gastroenterol Nutr 2010; 51: 140-145.

35. Jose FA, Garnett EA, Vittinghoff E, et al. Development of extraintestinal manifestations in pediatric patients with inflammatory bowel disease. Inflamm Bowel Dis 2009; 15: 63-68.

36. Deneau M, Jensen MK, Holmen J, Williams MS, Book LS, Guthery SL. Primary sclerosing cholangitis, autoimmune hepatitis, and overlap in Utah children: epidemiology and natural history. Hepatology 2013; 58: 1392-1400.

37. Billiet T, Vermeire S. Differences between adults and children: genetics and beyond. Expert Rev Gastaroenterol Hepatol 2015; 9: 191-196.

38. Paul T, Birnbaum A, Pal DK, et al. Distinct phenotype of early childhood inflammatory bowel disease. J Clin Gastroenterol 2006; 40: 583-586.

39. Kim S. Surgery in Pediatric Crohn's Disease: Indications, Timing and Post-Operative Management. Pediatr Gastroenterol Hepatol Nutr 2017; 20: 14-21.

40. Heyman MB, Kirschner BS, Gold BD, et al. Children with early-onset inflammatory bowel disease (IBD): analysis of a pediatric IBD consortium registry. J Pediatr 2005; 146: 35-40.

41. Kim HJ, Oh SH, Kim DY, et al. Clinical characteristics and long-term outcomes of paediatric crohn's disease: A single-centre experience. J Crohns Colitis 2017; 11: 157-164.

42. Hugot JP, Chamaillard M, Zouali $\mathrm{H}$, et al. Association of NOD2 leucine-rich repeat variants with susceptibility to Crohn's disease. Nature 2001; 411: 599-603.

43. Ahmad T, Armuzzi A, Bunce M, et al. The molecular classification of the clinical manifestations of Crohn's disease. Gastroenterology 2002; 122: 854-866.

44. Moeeni V, Day AS. Impact of inflammatory bowel disease upon growth in children and adolescents. ISRN Pediatr 2011; 2011: 36-45

45. Ezri J, Marques-Vidal P, Nydegger A. Impact of disease and treatments on growth and puberty of pediatric patients with inflammatory bowel disease. Digestion 2012; 85: 308-319.

46. Critch J, Day AS, Otley A, King-Moore C, Teitelbaum JE, Shashidhar $\mathrm{H}$; NASPGHAN IBD Committee. Use of enteral nutrition for the control of intestinal inflammation in pediatric Crohn disease. J Pediatr Gastroenterol Nutr 2012; 54: 298-305.

47. Murch SH, Walker-Smith JA. Nutrition in inflammatory bowel disease. Bailliere's Clin Gastroenterol 1998; 12: 719-738.
48. O'Morain C, Segal AW, Levi AJ. Elemental diet as primary treatment of acute Crohn's disease: a controlled trial. Br Med J (Clin Res Ed). 1984; 288: 1859-1862.

49. Zachos M, Tondeur M, Griffiths AM. Enteral nutritional therapy for induction of remission in Crohn's disease. Cochrane Database Syst Rev 2007; CD000542.

50. Gupta K, Noble A, Kachelries KE, et al. A novel enteral nutrition protocol for the treatment of pediatric Crohn's disease. Inflamm Bowel Dis 2013; 19: 1374-1378.

51. Mack DR, Langton C, Markowitz J, et al; Pediatric Inflammatory Bowel Disease Collaborative Research Group. Laboratory values for children with newly diagnosed inflammatory bowel disease. Pediatrics 2007; 119: 1113-1119.

52. Dubinsky MC, Lin YC, Dutridge D, et al. Serum immune responses predict rapid disease progression among children with Crohn's disease: immune responses predict disease progression. Am J Gastroenterol 2006; 101: 360-367.

53. Marsh RA, Bleesing JJ, Filipovich AH. Using flow cytometry to screen patients for X-linked lymphoproliferative disease due to SAP deficiency and XIAP deficiency. J Immunol Methods 2010; 362 $1-9$.

54. Gifford CE, Weingartner E, Villanueva J, et al. Clinical flow cytometric screening of SAP and XIAP expression accurately identifies patients with SH2D1A and XIAP/BIRC4 mutations. Cytometry B Clin Cytom 2014; 86: 263-271.

55. Sabery N, Bass D. Use of serologic markers as a screening tool in inflammatory bowel disease compared with elevated erythrocyte sedimentation rate and anemia. Pediatrics 2007; 119: e193-e199.

56. Prenzel F, Uhlig HH. Frequency of indeterminate colitis in children and adults with IBD - a metaanalysis J Crohns Colitis 2009; 3: 277-281.

57. McGovern DP, Kugathasan S, Cho JH. Genetics of inflammatory bowel diseases. Gastroenterology 2015; 149: 1163-1176.e2

58. Moran CJ, Klein C, Muise AM, Snapper SB. Very early-onset inflammatory bowel disease: gaining insight through focused discovery. Inflamm Bowel Dis 2015; 21: 1166-1175.

59. Newman B, Siminovitch KA. Recent advances in the genetics of inflammatory bowel disease. Curr Opin Gastroenterol 2005; 21: 401-407.

60. Schreiber S, Rosenstiel P, Albrecht M, Hampe J, Krawczak M. Genetics of Crohn disease, an archetypal inflammatory barrier disease. Nat Rev Genet 2005; 6: 376-388.

61. Parkes M, Barrett JC, Prescott NJ, et al. Sequence variants in the autophagy gene IRGM and multiple other replicating loci contribute to Crohn's disease susceptibility. Nat Genet 2007; 39: 830-832. 
62. Hampe J, Franke A, Rosenstiel P, et al. A genome-wide association scan of nonsynonymous SNPs identifies a susceptibility variant for Crohn disease in ATG16L1. Nat Genet 2007; 39: 207-211.

63. Kaser A, Lee AH, Franke A, et al. XBP1 links ER stress to intestinal inflammation and confers genetic risk for human inflammatory bowel disease. Cell 2008; 134: 743-756.

64. Chan IH, Wu V, McCauley S, Grimm EA, Mumm JB. IL-10: Expanding the immune oncology horizon. Receptors Clin Investig 2015; 2.

65. Eskdale J, Kube D, Tesch H, Gallagher G. Mapping of the human IL10 gene and further characterization of the 5 ' flanking sequence. Immunogenetics 1997; 46: $120-128$

66. Pestka S, Krause CD, Sarkar D, Walter MR, Shi Y, Fisher PB. Interleukin-10 and related cytokines and receptors. Annu Rev Immunol 2004; 22: 929-979.

67. Commins S, Steinke JW, Borish L. The extended IL-10 superfamily: IL-10, IL-19, IL-20, IL-22, IL-24, IL-26, IL-28, and IL-29. J Allergy Clin Immunol 2008; 121: 1108-1111.

68. Fiorentino DF, Zlotnik A, Vieira P, et al. IL-10 acts on the antigen-presenting cell to inhibit cytokine production by Th1 cells. J Immunol 1991; 146: 34443451 .

69. Glocker EO, Kotlarz D, Boztug K, et al. Inflammatory bowel disease and mutations affecting the interleukin-10 receptor. N Engl J Med 2009; 361: 2033-2045.

70. Chen R, Giliani S, Lanzi G, et al. Whole-exome sequencing identifies tetratricopeptide repeat domain 7A (TTC7A) mutations for combined immunodeficiency with intestinal atresias. J Allergy Clin Immunol 2013; 132: 656-664.e17.

71. Avitzur Y, Guo C, Mastropaolo LA, et al. Mutations in tetratricopeptide repeat domain 7A result in a severe form of very early onset inflammatory bowel disease. Gastroenterology 2014; 146: 1028-1039.

72. Samuels ME, Majewski J, Alirezaie N, et al. Exome sequencing identifies mutations in the gene TTC7A in French-Canadian cases with hereditary multiple intestinal atresia. J Med Genet 2013; 50: 324-329.

73. Woo SK, Kwon HM. Adaptation of kidney medulla to hypertonicity: role of the transcription factor TonEBP. Int Rev Cytol 2002; 215: 189-202.

74. Neuhofer W, Beck FX. Cell survival in the hostile environment of the renal medulla. Annu Rev Physiol 2005; 67: 531-555

75. Lee JH, Kim M, Im YS, Choi W, Byeon SH, Lee HK. NFAT5 induction and its role in hyperosmolar stressed human limbal epithelial cells. Invest Ophthalmol Vis Sci 2008; 49: 1827-1835.

76. Schilli R, Breuer RI, Klein F, et al. Comparison of the composition of faecal fluid in Crohn's disease and ulcerative colitis. Gut 1982; 23: 326-332.
77. Vernia P, Gnaedinger A, Hauck W, Breuer RI. Organic anions and the diarrhea of inflammatory bowel disease. Dig Dis Sci 1988; 33: 1353-1358.

78. Vertzoni M, Goumas K, Soderlind E, et al Characterization of the ascending colon fluids in ulcerative colitis. Pharm Res 2010; 27: 1620-1626.

79. Chandrakasan S, Venkateswaran S, Kugathasan S Nonclassic inflammatory bowel disease in young infants: Immune dysregulation, polyendocrinopathy, enteropathy, X-linked syndrome, and other disorders. Pediatr Clin North Am 2017; 64: 139-160.

80. Lopez-Herrera G, Tampella G, Pan-Hammarstrom Q et al. Deleterious mutations in LRBA are associated with a syndrome of immune deficiency and autoimmunity. Am J Hum Genet 2012; 90: 986-1001.

81. Lo B, Zhang K, Lu W, et al. Autoimmune Disease. Patients with LRBA deficiency show CTLA4 loss and immune dysregulation responsive to abatacept therapy. Science 2015; 349: 436-440.

82. Kimura Y, Walco GA, Sugarman E, Conte PM, Schanberg LE. Treatment of pain in juvenile idiopathic arthritis: a survey of pediatric rheumatologists. Arthritis Rheum 2006; 55: 81-85.

83. Chae JJ, Wood G, Richard K, et al. The familial Mediterranean fever protein, pyrin, is cleaved by caspase- 1 and activates NF-kappaB through its N-terminal fragment. Blood 2008; 112: 1794-1803.

84. Karban A, Dagan E, Eliakim R, et al. Prevalence and significance of mutations in the familial Mediterranean fever gene in patients with Crohn's disease. Genes Immun 2005; 6: 134-139.

85. Liston P, Roy N, Tamai K, et al. Suppression of apoptosis in mammalian cells by NAIP and a related family of IAP genes. Nature 1996; 379: 349-353.

86. Duckett CS, Nava VE, Gedrich RW, et al. A conserved family of cellular genes related to the baculovirus iap gene and encoding apoptosis inhibitors. EMBO J 1996; 15: 2685-2694.

87. Deveraux QL, Takahashi R, Salvesen GS, Reed JC. X-linked IAP is a direct inhibitor of cell-death proteases. Nature 1997; 388: 300-304.

88. Wilkinson JC, Cepero E, Boise LH, Duckett CS Upstream regulatory role for XIAP in receptormediated apoptosis. Mol Cell Biol 2004; 24: 7003 7014 .

89. Worthey EA, Mayer AN, Syverson GD, et al. Making a definitive diagnosis: successful clinical application of whole exome sequencing in a child with intractable inflammatory bowel disease. Genet Med 2011; 13: 255-262.

90. Punzi L, Furlan A, Podswiadek M, et al. Clinical and genetic aspects of Blau syndrome: a 25-year follow-up of one family and a literature review. Autoimmun Rev 2009; 8: 228-232.

91. Sfriso P, Caso F, Tognon S, Galozzi P, Gava A, Punzi L. Blau syndrome, clinical and genetic aspects. Autoimmun Rev 2012; 12: 44-51. 
92. Raiji VR, Miller MM, Jung LK. Uveitis in Blau syndrome from a de novo mutation of the NOD2/ CARD15 gene. J AAPOS 2011; 15: 205-207.

93. Shaw MH, Kamada N, Warner N, Kim YG, Nunez G. The ever-expanding function of NOD2: autophagy, viral recognition, and $\mathrm{T}$ cell activation. Trends Immunol 2011; 32: 73-79.

94. Cooney R, Baker J, Brain O, et al. NOD2 stimulation induces autophagy in dendritic cells influencing bacterial handling and antigen presentation. Nat Med 2010; 16: 90-97.

95. Travassos LH, Carneiro LA, Ramjeet M, et al. Nod1 and Nod2 direct autophagy by recruiting ATG16L1 to the plasma membrane at the site of bacterial entry. Nat Immunol 2010; 11: 55-62.

96. Hisamatsu T, Suzuki M, Reinecker HC, Nadeau WJ, McCormick BA, Podolsky DK. CARD15/ NOD2 functions as an antibacterial factor in human intestinal epithelial cells. Gastroenterology 2003; 124: 993-1000.

97. Bertin J, Guo Y, Wang L, et al. CARD9 is a novel caspase recruitment domain-containing protein that interacts with BCL10/CLAP and activates NF-kappa B. J Biol Chem 2000; 275: 41082-41086.

98. Hsu YM, Zhang Y, You Y, et al. The adaptor protein CARD9 is required for innate immune responses to intracellular pathogens. Nat Immunol 2007; 8: 198205.

99. Poeck H, Bscheider M, Gross O, et al. Recognition of RNA virus by RIG-I results in activation of CARD9 and inflammasome signaling for interleukin 1 beta production. Nat Immunol 2015; 11: 63-69.

100. Gringhuis SI, Wevers BA, Kaptein TM, et al. Selective C-Rel activation via Malt 1 controls anti-fungal $\mathrm{T}(\mathrm{H})$ 17 immunity by dectin-1 and dectin-2. PLoS Pathog 2011; 7: e1001259.

101. Glocker EO, Hennigs A, Nabavi M, et al. A homozygous CARD9 mutation in a family with susceptibility to fungal infections. N Engl J Med 2009; 361: 1727-1735.

102. Turck D, Michaelsen KF, Shamir R, et al; on Behalf of the ESPGHAN Committee on Nutrition.World Health Organization 2006 child growth standards and 2007 growth reference charts: A discussion paper by the Committee on Nutrition of the European Society for Pediatric Gastroenterology, Hepatology, and Nutrition. J Pediatr Gastroenterol Nutr 2006; 57: 258-264.
103. Weinstein TA, Levine M, Pettei MJ, Gold DM, Kessler $\mathrm{BH}$, Levine JJ. Age and family history at presentation of pediatric inflammatory bowel disease. J Pediatr Gastroenterol Nutr 2003; 37: 609-613.

104. Heuschkel R, Salvestrini C, Beattie RM, Hildebrand H, Walters T, Griffiths A. Guidelines for the management of growth failure in childhood inflammatory bowel disease. Inflamm Bowel Dis 2008; 14: 839-849.

105. Chong SK, Blackshaw AJ, Boyle S, Williams CB, Walker-Smith JA. Histological diagnosis of chronic inflammatory bowel disease in childhood. Gut 1985; 26: 55-59.

106. Cameron DJ. Upper and lower gastrointestinal endoscopy in children and adolescents with Crohn's disease: a prospective study. J Gastroenterol Hepatol 1991; 6: 355-358

107. Cameron D. Diagnostic role of upper gastrointestinal endoscopy in pediatric inflammatory bowel disease. J Pediatr Gastroenterol Nutr 2005; 40: 383.

108. Levine A, Koletzko S, Turner D, et al; European Society of Pediatric Gastroenterology, Hepatology, and Nutrition. ESPGHAN revised porto criteria for the diagnosis of inflammatory bowel disease in children and adolescents. J Pediatr Gastroenterol Nutr 2013; 58: 795-806.

109. Robert ME, Tang L, Hao LM, Reyes-Mugica M. Patterns of inflammation in mucosal biopsies of ulcerative colitis: perceived differences in pediatric populations are limited to children younger than 10 years. Am J Surg Pathol 2004; 28: 183-189.

110. Washington K, Greenson JK, Montgomery EA, et al Histopathology of ulcerative colitis in initial rectal biopsy in children. Am J Surg Pathol 2002; 26: 1441 1449 .

111. Levine A, Griffiths A, Markowitz J, et al. Pediatric modification of the Montreal classification for inflammatory bowel disease: the Paris classification. Inflamm Bowel Dis 2011; 17:1314-1321.

112. Rajwal SR, Puntis JW, McClean P, et al. Endoscopic rectal sparing in children with untreated ulcerative colitis. J Pediatr Gastroenterol Nutr 2004; 38: 66-69. 